British Journal of Nutrition (2021), 125, 1188-1200

(C) The Author(s), 2020. Published by Cambridge University Press on behalf of The Nutrition Society. This is an Open Access article, distributed under the terms of the Creative Commons Attribution licence (http://creativecommons.org/licenses/by/4.0/), which permits unrestricted re-use, distribution, and reproduction in any medium, provided the original work is properly cited.

\title{
Associations of the dietary World Cancer Research Fund/American Institute for Cancer Research (WCRF/AICR) recommendations with patient-reported outcomes in colorectal cancer survivors 2-10 years post-diagnosis: a cross-sectional analysis
}

\author{
Marlou-Floor Kenkhuis ${ }^{1 *}$, Bernadette W. A. van der Linden ${ }^{2}$, Jose J. L. Breedveld-Peters ${ }^{1}$, Janna L. Koole ${ }^{1}$, \\ Eline H. van Roekel ${ }^{1}$, Stéphanie O. Breukink ${ }^{3}$, Floortje Mols ${ }^{4}$, Matty P. Weijenberg ${ }^{1}$ and Martijn J. L. Bours ${ }^{1}$ \\ ${ }^{1}$ Department of Epidemiology, GROW School for Oncology and Developmental Biology, Maastricht University, 6200 MD \\ Maastricht, the Netherlands \\ ${ }^{2}$ Department of Epidemiology, GROW School for Oncology and Developmental Biology, Maastricht University as Part of an \\ Internship from the Health Sciences Research Master of the Faculty of Health, Medicine and Life Sciences, Maastricht University, \\ 6200 MD Maastricht, the Netherlands \\ ${ }^{3}$ Department of Surgery, GROW School for Oncology and Developmental Biology, Maastricht University Medical Centre+, 6200 \\ MD Maastricht, the Netherlands \\ ${ }^{4}$ Department of Medical and Clinical Psychology, Tilburg University, 5037 AB Tilburg, the Netherlands
}

(Submitted 20 May 2020 - Final revision received 15 July 2020 - Accepted 5 August 2020 - First published online 22 October 2020)

Abstract

The World Cancer Research Fund and American Institute for Cancer Research (WCRF/AICR) advise cancer survivors to follow their lifestyle recommendations for cancer prevention. Adhering to these recommendations may have beneficial effects on patient-reported outcomes after a cancer diagnosis, but evidence is scarce. We aimed to assess associations of the individual dietary WCRF/AICR recommendations regarding fruit and vegetables, fibre, fast foods, red and processed meat, sugar-sweetened drinks and alcohol consumption with patient-reported outcomes in colorectal cancer (CRC) survivors. Cross-sectional data of 150 stage I-III CRC survivors, 2-10 years post-diagnosis, were used. Dietary intake was measured by 7-d dietary records. Validated questionnaires were used to measure health-related quality of life (HRQoL), fatigue and neuropathy. Confounder-adjusted linear regression models were used to analyse associations of each WCRF/AICR dietary recommendation with patient-reported outcomes. Higher vegetable intake (per $50 \mathrm{~g})$ was associated with better global QoL ( $\beta 2 \cdot 6$; $95 \%$ CI 0.6, 4.7), better physical functioning $(3 \cdot 3 ; 1 \cdot 2,5 \cdot 5)$ and lower levels of fatigue $(-4 \cdot 5 ;-7 \cdot 6,-1 \cdot 4)$. Higher fruit and vegetables intake (per $100 \mathrm{~g})$ was associated with better physical functioning $(3 \cdot 2 ; 0 \cdot 8,5 \cdot 5)$ and higher intake of energy-dense food (per $100 \mathrm{~kJ} / 100 \mathrm{~g}$ ) with worse physical functioning $(-4 \cdot 2 ;-7 \cdot 1,-1 \cdot 2)$. No associations of dietary recommendations with neuropathy were found. These findings suggest that adhering to specific dietary WCRF/AICR recommendations is associated with better HRQOL and less fatigue in CRC survivors. Although the recommendations regarding healthy dietary habits may be beneficial for the well-being of CRC survivors, longitudinal research is warranted to gain insight into the direction of associations.

Key words: Colorectal cancer survivorship: Lifestyle recommendations: Diet: Health-related quality of life: Fatigue: Neuropathy

Globally, the number of colorectal cancer (CRC) survivors continues to rise, mainly due to population ageing, screening and improved treatments ${ }^{(1-3)}$. CRC survivors frequently report decreased health-related quality of life (HRQoL) due to persisting problems related to the cancer and/or its treatment and the presence of co-morbidities ${ }^{(4-6)}$. Two commonly experienced problems are cancer-related fatigue and chemotherapy-induced peripheral neuropathy (CIPN). Cancer-related fatigue has estimated prevalence rates of 41 and $35 \%$ among short-term $(<5$ years post-diagnosis) and long-term ( $>5$ years post-diagnosis) CRC survivors, respectively ${ }^{(7)}$. Approximately two-thirds of patients after chemotherapy cessation experience CIPN symptoms like

Abbreviations: CIPN, chemotherapy-induced peripheral neuropathy; CRC, colorectal cancer; HRQoL, health-related quality of life; MVPA, moderate-to-vigorous physical activity; UPF, ultra-processed foods; WCRF/AICR, World Cancer Research Fund/American Institute for Cancer Research.

* Corresponding author: Marlou-Floor Kenkhuis, email m.kenkhuis@maastrichtuniversity.nl 
tingling hands and feet, with falling rates to approximately onethird of patients at 6 months ${ }^{(8)}$. Both fatigue and CIPN can negatively affect physical functioning and daily living up to 10 years post-treatment ${ }^{(9-11)}$. It is therefore of interest to identify modifiable factors, such as lifestyle factors, related to long-term HRQOL outcomes, fatigue and CIPN that provide input for recommendations or interventions aimed at improving the health and well-being of CRC survivors.

In 2018, the World Cancer Research Fund and the American Institute for Cancer Research (WCRF/AICR) updated their lifestyle recommendations based on extensive systematic reviews of evidence on diet, nutrition, physical activity, body weight and risk of cancer ${ }^{(12)}$. As the evidence to formulate-specific recommendations for cancer survivors is insufficient to date, WCRF/AICR advises cancer survivors to follow the lifestyle recommendations for cancer prevention. Lifestyle behaviours such as higher levels of physical activity, a healthy body weight and consumption of diets low in red meat, high in vegetables and high in fibre are associated with less recurrence and increased survival in cancer survivors, including CRC survivors ${ }^{(13-16)}$, but are also likely to be relevant for increasing $\mathrm{HRQOL}^{(17-20)}$ and decreasing fatigue and neuropathy ${ }^{(21)}$. Most evidence on patient-reported outcomes has been derived from studies on physical activity and body weight. Studies have shown that lower levels of physical activity as well as not meeting physical activity guidelines were significantly associated with lower HRQOL in CRC survivors up to 10 years post-diagnosis ${ }^{(22-24)}$, whereas higher levels of moderate-to-vigorous physical activity (MVPA) were found to be associated with lower levels of fatigue and neuropathy ${ }^{(9,25,26)}$. Studies in CRC survivors have found that having a higher BMI was associated with lower HRQOL outcomes ${ }^{(19,27-34)}$

Nutrition has a large contribution in the lifestyle recommendations, as five out of seven recommendations are focused on nutrition. The dietary recommendations comprise consuming a sufficient amount of fruit and vegetables and fibre, whilst limiting consumption of red and processed meat, fast foods, sugarsweetened drinks and alcohol. However, only few studies have evaluated the potential role of dietary intake on HRQoL, fatigue and neuropathy in the specific population of CRC survivors, and results have been inconsistent. Two cross-sectional studies that used a single- or a two-item question to assess fruit and vegetables intake pointed towards a beneficial association of meeting the recommendation of five servings per $d$ of fruit and vegetables with higher $\mathrm{HRQOL}^{(20,35)}$. Additionally, moderate alcohol drinkers (weekly alcoholic drinks 1-14 for women and 1-21 for men) reported higher physical, role and social functioning and lower fatigue compared with non-drinkers ${ }^{(20,36)}$, while no significant association was found between HRQOL and heavy drinking (weekly alcoholic drinks $>14$ for women and $>21$ for men ${ }^{(20)}$. One cross-sectional study in survivors of different cancers, including 113 CRC survivors, determined diet quality from 24-h recalls and found that higher diet quality (Healthy Eating Index scores above 80) was positively associated with better physical HRQoL outcomes ${ }^{(31)}$. A longitudinal study showed that CRC patients following a 'Western' diet characterised by high consumption of potatoes, red and processed meat, poultry and cakes had lower chances to improve in physical functioning 1 year post-treatment compared with patients following a diet rich in fruit and vegetables ${ }^{(37)}$. To our knowledge no studies have assessed an association between fruit and vegetables and CIPN in CRC survivors; one study in breast cancer patients receiving taxane treatment, however, found no association ${ }^{(21)}$. Nevertheless, several small intervention studies in diabetic neuropathy showed that a low-fat, plant-based diet was associated with decreased pain of diabetic neuropathy in patients experiencing diabetic neuropathy complaints, increasing the plausibility that dietary factors may also be associated with CIPN complaints after $\mathrm{CRC}^{(38,39)}$.

Recently, we reported that higher adherence to the 2007 WCRF/AICR lifestyle recommendations (combined into an overall adherence score) was related with better physical functioning and with less fatigue in CRC survivors 2-10 years postdiagnosis $^{(17)}$. As the majority of recommendations is focused on nutrition, but there is scarce evidence on how the individual dietary recommendations are related to HRQOL after CRC, we aimed to further analyse the role of the updated individual dietary recommendations from the 2018 WCRF/AICR guidelines in this paper. Making use of the food group classification system proposed in the $2018 \mathrm{WCRF} / \mathrm{AICR}$ Score ${ }^{(40)}$, we aimed to assess associations of the individual dietary recommendations regarding intake of fruit and vegetables, dietary fibre, fast foods, red and processed meat, sugar-sweetened drinks and alcohol consumption in relation to HRQoL, fatigue and CIPN in CRC survivors $2-10$ years post-diagnosis.

\section{Methods}

\section{Study design and population}

Data from the cross-sectional part of the Energy for Life after ColoRectal cancer (EnCoRe) study were used. This part of the EnCoRe study was set up to evaluate the influence of lifestyle factors on HRQoL outcomes in long-term (2-10 years posttreatment) stage I-III CRC survivors ${ }^{(41)}$. Study measurements were conducted between May 2012 and December 2013. Patients diagnosed with and treated for stage I-III CRC at the Maastricht University Medical Center+ in the Netherlands between 2002 and 2010 were identified via the Netherlands Cancer Registry and invited to participate by mail. Reasons for exclusion are shown in Fig. 1. The study was approved by the Medical Ethics Committee of the University Hospital Maastricht and Maastricht University (Netherlands Trial Register no. NL6904) and patients provided written informed consent before participation.

\section{Data collection}

Data were collected by means of trained dietitians, who visited all patients at their homes to perform study measurements and leave behind questionnaires and a dietary record according to predefined standard operating procedures.

Dietary intake. Participants were asked to fill out a structured dietary record to obtain quantitative data on food and beverage consumption on seven consecutive days. In the dietary record, participants reported consumed meals, food and beverages with details on brand names, portion sizes and preparation. 

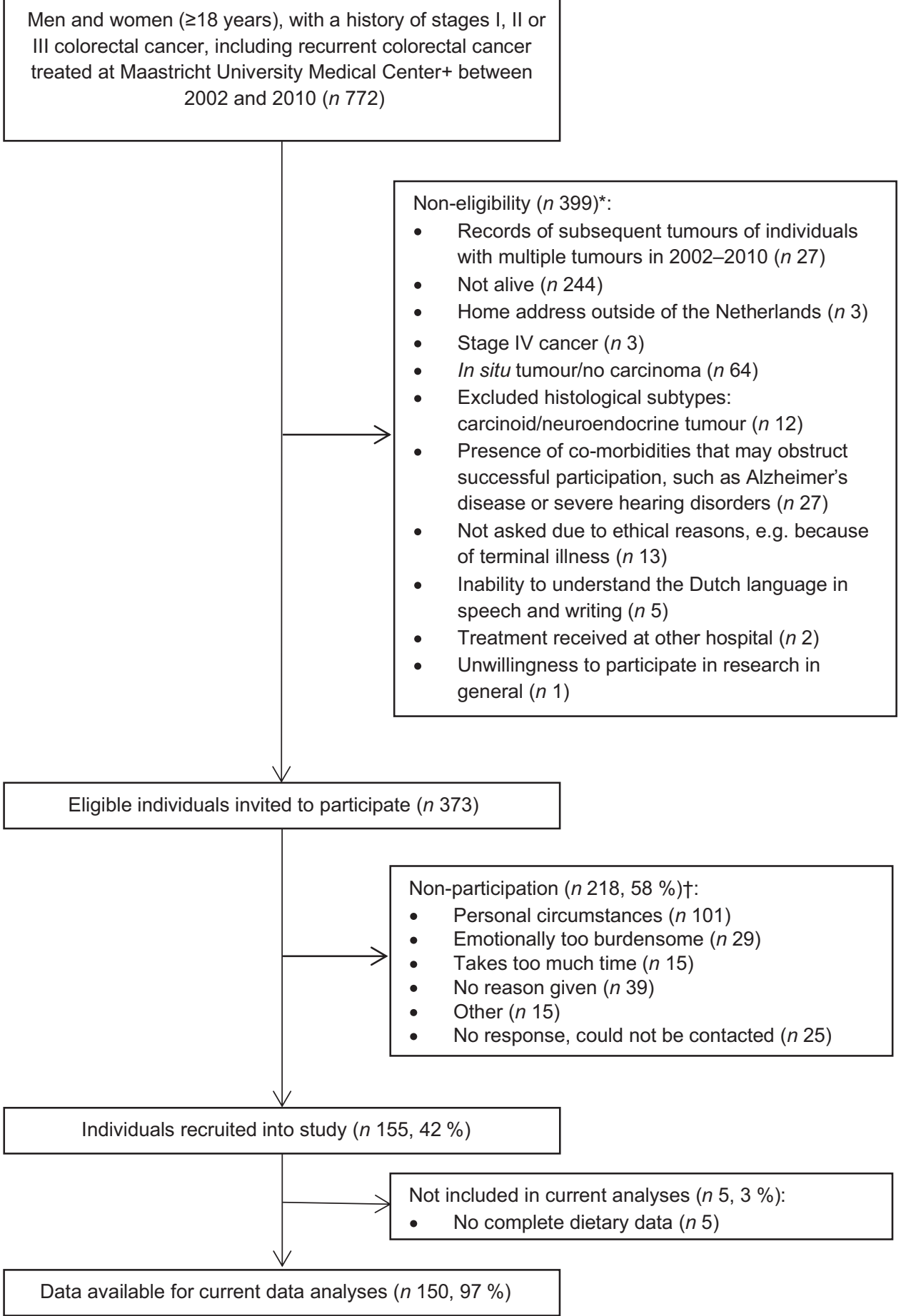

Fig. 1. Flow diagram of inclusion of colorectal cancer survivors. * Reasons for non-eligibility are given in order of exclusion. Totals do not add up because some exclusion criteria applied concurrently. † Totals do not add up because some individuals reported multiple reasons for non-participation.

Participants received oral and written instructions on how to fill out the dietary record. Additionally, all completed dietary records were checked by the dietitians. When necessary, incomplete and/or inconsistent entries of the dietary record were clarified with the help of the participant.

Daily dietary intake was calculated utilising food calculation software (Compl-eat, Wageningen University) and based on the Dutch Food Composition database (NEVO-2011), using existing or specifically created dietary food groups in the software based on the 2018 WCRF/AICR dietary sub-recommendations (i.e. groups for fruit, vegetables, alcohol, fast foods, red meat, processed meat and sugar-sweetened drinks). Fruit and vegetable consumption $(\mathrm{g} / \mathrm{d})$ was calculated from the reported use of all fresh, frozen, dried and canned vegetables and fruit without added sugar. Calculation of total dietary fibre intake $(\mathrm{g} / \mathrm{d})$ and alcohol intake (i.e. ethanol in $\mathrm{g} / \mathrm{d}$ ) was based on the nutrient 
value from the food calculation table for the reported overall dietary intake.

The created food group for fast foods deserves particular attention. In agreement with the National Cancer Institute ${ }^{(40)}$, the fast food group was operationalised based on the group of ultra-processed foods (UPF) according to the NOVA classification system $^{(42)}$. The NOVA classification system classifies food groups based on the extent of processing, and the UPF group contains food such as sweet or savoury packaged snacks and pre-prepared dishes. The UPF list from the NOVA classification was adapted by the National Cancer Institute to be in line with the WCRF/AICR report (i.e. food products made from white flour $(\text { e.g. white bread, rice and pasta) })^{(12)}$, national guidelines and to ensure that the adapted UPF group did not include food already accounted for in other dietary recommendations (i.e. sugarsweetened drinks and red and processed meats). In the present study, the availability of extensive 7-d dietary records allowed us to make additional precise distinctions between products, compared with most previous studies based on FFQ. This led to additional food in our adapted UPF compared with the adapted UPF from National Cancer Institute (e.g. fruit yogurts). Our adapted UPF list is included in the online Supplementary material to show the food we included. For the fast food recommendation, we calculated the energy percentage of all food included in the UPF group based on participants' self-reported intake.

Red meat consumption $(\mathrm{g} / \mathrm{d})$ was based on the intake of any kind of fresh raw red meat (including beef, pork, lamb and goat) that still needed to be prepared before consumption. Intake of processed meat $(\mathrm{g} / \mathrm{d})$ included intake of any meat that had been preserved by smoking, curing, salting or addition of chemical preservatives and was ready for consumption without preparation. This also included all processed meat in mixed food containing processed meats, such as soups or sausage rolls.

Sugar-sweetened drinks $(\mathrm{g} / \mathrm{d})$ included drinks with natural sugar, like fruit juices, as well as soft drinks. Drinks to which sugar was added by participants (e.g. coffee) were not included in the sugar-sweetened drink category.

Methods and procedures applied for the assessment and coding of dietary records are extensively explained in detail in Breedveld et al ${ }^{(17)}$. Based on a random sample of dietary records ( $n$ 16, i.e. $10 \%$ of all dietary records), agreement in coding between two dietitians of the EnCoRe study was evaluated and found to be high (ICC > 0.87).

Patient-reported outcomes. Patient-reported outcomes were measured comprehensively through several generic and cancer-specific validated questionnaires. Cancer-specific HRQOL was measured by the European Organization for the Research and Treatment of Cancer Quality of Life Questionnaire-Core 30 (EORTC QLQ-C30) ${ }^{(43)}$. The EORTC QLQ-C30 is a thirty-item cancer-specific questionnaire composed of five functioning scales (physical, role, cognitive, emotional and social functioning), three symptom scales (fatigue, pain, and nausea and vomiting), a global health/QoL scale and a number of items for specific cancer-/treatment-related symptoms. The scales have a 100-point score range, with higher scores on the global QoL and functioning scales reflecting better HRQOL or functioning, whereas higher symptom scale scores indicate more symptoms (i.e. worse fatigue). In addition, the recently established summary score (SumSc) developed by the EORTC Quality of Life Group was used. The SumSc was calculated from the mean of 13 of the 15 QLQ-C30 scores (excluding the financial difficulties and global QoL questions) ${ }^{(44)}$.

In addition to the fatigue symptom scale from the EORTC QLQC30, fatigue was assessed in more detail by the Checklist Individual Strength (CIS) ${ }^{(45)}$. This questionnaire consists of twenty items with a seven-point Likert scale, a total score was derived by the summation of the items, ranging from 20 to 140 points with higher scores indicating worse fatigue. The CIS was originally developed and validated in patients with chronic fatigue syndrome ${ }^{(46)}$ but has also been applied in cancer survivors ${ }^{(47)}$.

To measure symptoms and complaints related to CIPN, the EORTC QLQ CIPN20 was used, consisting of sensory (nine items), motor (seven items) and autonomic subscales (two items) and a summary score (eighteen items) (excluding two conditional items $)^{(48)}$. All scale scores were linearly converted to a 0-100 scale $^{(49)}$. Higher scores on the CIPN20 scales indicate higher levels of neuropathy or more neuropathy-related complaints.

Lifestyle, clinical and sociodemographic factors. The Short QUestionnaire to ASsess Health-enhancing physical activity (SQUASH) was used to determine habitual activity level ${ }^{(50)}$, assessing time spent on commuting, household, work and leisure time activities in the past week. Time spent on MVPA was calculated $^{(51)}$, and this was used to assess whether participants adhered to the physical activity recommendation of at least 150 min of MVPA per week. For objective measurement of sedentary time, the validated tri-axial MOX activity metre was used (Maastricht Instruments B.V.), as described previously by van Roekel et $a l .{ }^{(52)}$. Briefly, the accelerometer was worn on the upper thigh for seven consecutive days $(24 \mathrm{~h} / \mathrm{d})$ to assess average time spent per $\mathrm{d}$ in sedentary behaviour (i.e. sitting/lying with a low level of energy expenditure, during waking hours). Body composition measurements were performed by trained dietitians in a standardised way during home visits. Subjects' weight was measured in light clothing without shoes on an electronic scale (Seco Ltd, type 861) and rounded to the nearest tenth of a kg. Height was measured in duplicate with the subject standing barefoot with heels together, arms at the side and head in the Frankfort horizontal plane with a portable stadiometer at the first home visit and measured to the nearest tenth of a $\mathrm{cm}$. Measured weight and mean height were used to determine BMI in $\mathrm{kg} / \mathrm{m}^{2}$. BMI was categorised according to the WHO guidelines as underweight $\left(\mathrm{BMI}<18.5 \mathrm{~kg} / \mathrm{m}^{2}\right)$, normal weight $(18.5 \leq \mathrm{BMI}$ $\left.<25 \mathrm{~kg} / \mathrm{m}^{2}\right)$, overweight $\left(25 \leq \mathrm{BMI}<30 \mathrm{~kg} / \mathrm{m}^{2}\right)$ or obesity $\left(\mathrm{BMI} \geq 30 \mathrm{~kg} / \mathrm{m}^{2}\right)^{(53)}$. Waist circumference was measured midway between the lower rib margin and the iliac crest with a circumeter (type 05335, Premed) in cm; duplicate measurements were performed and the mean value was used. Clinical information (i.e. cancer stage, chemotherapy/radiotherapy treatment and tumour site) was collected through the Netherlands Cancer Registry. Selfreported data were collected on other factors, such as age, sex, education level, current smoking status and presence of co-morbidities. Co-morbidities were assessed using the Self-Administered Comorbidity Questionnaire ${ }^{(54)}$. 


\section{Statistical analyses}

Descriptive statistics (means and standard deviations or frequencies and percentages) were calculated to describe main sample characteristics, including intake of fruit and vegetables, dietary fibre, energy-dense food, fast foods, red and processed meat, sugar-sweetened drinks and alcoholic drinks.

Confounder-adjusted linear regression models were used to assess associations of each of the individual dietary recommendations in relation to the separate patient-reported outcomes. Six dietitians reached consensus on the relevant differences for each dietary recommendation, based on the recommended portion per $\mathrm{d}$ and on relevant differences in portion sizes (e.g. $100 \mathrm{~g}$ of fruit and vegetables is one portion and $10 \mathrm{~g}$ of ethanol is one alcoholic consumption). The individual dietary recommendations were modelled continuously per relevant difference for each recommendation, as defined a priori. Additionally, alcoholic consumption was also modelled as a categorical variable: no alcohol consumption; moderate alcohol consumption: 1-14 glasses per week (reference category) and heavy alcohol consumption: $>14$ glasses per week for both men and women. HRQOL outcomes included global QoL, physical functioning, role functioning, social functioning and summary score (EORTC QLQ-C30); fatigue (EORTC and CIS) and neuropathy scales (CIPN20). CIPN outcomes were only analysed for the subgroup of patients who received chemotherapy. A priori-defined confounders included in analyses were age (years), sex, BMI $\left(\mathrm{kg} / \mathrm{m}^{2}\right)$, MVPA (h/week), sedentary behaviour $(\mathrm{h} / \mathrm{d})$, number of co-morbidities $(0,1, \geq 2)$, smoking (current, non-current), education level (low, medium and high), tumour stages (I, II and III), chemotherapy (yes, no), time since diagnosis (years) and total energy intake (kJ/week).

Two sensitivity analyses were performed. The first was a logistic regression analysis with dichotomised patient-reported outcomes using sex-specific median values as cut-off because some of the outcomes were not normally distributed ${ }^{(19,52)}$. Another sensitivity analysis was a linear regression analysis excluding participants with outliers in dietary data. Outliers were identified by two methods. First, outliers in dietary data were based on the top and bottom $0.5 \%$ of the distribution of the ratio of energy intake to the BMR, where BMR was estimated from body weight by using Schofield's age- and sex-specific equations ${ }^{(55)}$. Second, outliers were based on nutrient values exceeding three times the interquartile range from the upper quartile within the fifth quintile of the nutrient distribution ${ }^{(56)}$.

Statistical analyses were performed using IBM SPSS Statistics (version 23, IBM Corporation) with statistical significance set at $P<0.05$ (two-tailed).

\section{Results}

\section{Descriptives}

In total, 373 eligible CRC survivors were invited to participate, of whom $155(41.6 \%)$ were included in the cross-sectional part of the EnCoRe study (Fig. 1). Five survivors did not provide dietary data and were therefore excluded from the current analyses. The remaining $150 \mathrm{CRC}$ survivors recruited in the current analyses consisted of ninety-three males (62\%) and fifty-seven females (38\%) and were on average 69.7 (SD 8.7 ) years of age and diagnosed with CRC 5.7 (SD 1.8) years before study participation (Table 1 ). Based on BMI, $26 \cdot 2 \%$ of participants were underweight or normal weight (one participant was underweight), $45.6 \%$ were overweight and $28.2 \%$ were obese. A total of 136 (90.7\%) survivors adhered to the physical activity recommendation ( $\geq 150 \mathrm{~min} /$ week of MVPA) and $11 \%$ were current smokers. Approximately half of the participants had colon cancer (53.3\%) and the other half had rectum cancer ( $46.7 \%$ ). Regarding selfreported co-morbidities, $24.8 \%$ of the participants reported no co-morbidity, whereas half of the participants $(50 \cdot 3 \%)$ reported two or more co-morbid conditions.

In Tables 2 and 3, an overview is given of the individual dietary recommendations and the adherence of included CRC survivors based on reported intake. Cut-off values are based on the National Cancer Institute operationalisation of the WCRF/AICR lifestyle recommendations ${ }^{(40)}$. Mean total energy intake was 9126 (SD 1753) kJ/d in men and 6697 (SD 1380) in women. Mean total intake of fruit and vegetables per $\mathrm{d}$ was 273 (SD 131) g, which was composed of 131 (SD 94) g of fruit and 142 (SD 70) $g$ of vegetables. A total of $18.0 \%$ of participants met the recommendation of eating $400 \mathrm{~g} / \mathrm{d}$ of fruit and vegetables. Mean dietary fibre intake was 21.1 (SD 6.9) g/d, with $9.3 \%$ meeting the recommendation of $30 \mathrm{~g} / \mathrm{d}$. Mean energy density of food was 701 (sD 112) kJ/100 g per d, and the mean energy percentage of daily fast food intake was $31 \cdot 4$ (sD 11.1) \%. Mean intake of sugar-sweetened drinks was 97 (SD 150) g/d. For red meat, the mean intake was 592 (SD 295) g/week and for processed meat 45 (SD 32) g/d. Only two persons (1.3\%) met the recommendation of limiting processed meat $(<3 \mathrm{~g} / \mathrm{d})$ and not exceeding $500 \mathrm{~g}$ of red meat per week. Total alcohol intake per d was 19.4 (SD 16.3) $\mathrm{g} / \mathrm{d}$ in men and $7.1(\mathrm{sD} 8.3) \mathrm{g} / \mathrm{d}$ in women; $8.6 \%$ of men and $17.5 \%$ of women did not drink alcohol.

\section{Multi-variable analyses}

Tables 4 and 5 present the results of the unadjusted and confounderadjusted linear regression analyses of dietary intake variables with HRQOL subscales, fatigue and CIPN. A higher intake of fruit and vegetables was associated with significantly better physical functioning $(\beta / 100 \mathrm{~g} 3 \cdot 2 ; 95 \% \mathrm{CI} 0 \cdot 8,5 \cdot 5)$. This association appeared to be mostly driven by vegetable intake, as higher vegetable intake was significantly associated with better physical functioning ( $\beta / 50 \mathrm{~g} \mathrm{3 \cdot 3;95 \%}$ CI $1.2,5.5)$, whereas non-significant results were obtained for fruit intake $(\beta / 50 \mathrm{~g} 1 \cdot 2 ; 95 \% \mathrm{CI}-0 \cdot 5,2 \cdot 8)$. In addition, higher vegetable intake was associated with better global QoL $(2 \cdot 6 ; 95 \%$ CI $0 \cdot 6,4 \cdot 7)$ and lower levels of fatigue as measured by the CIS $(-4.5 ; 95 \% \mathrm{CI}$ $-7 \cdot 6,-1 \cdot 4)$. Higher intake of energy-dense food was associated with worse physical functioning ( $\beta / 100 \mathrm{~kJ}$ per $100 \mathrm{~g}-4 \cdot 2 ; 95 \% \mathrm{CI}-7 \cdot 1$, $-1 \cdot 2$ ). When alcohol was analysed as a categorical variable, participants who did not drink alcohol had significantly lower levels on the physical functioning scale $(\beta-10 \cdot 2 ; 95 \% \mathrm{CI}-19 \cdot 7,-0 \cdot 8)$, role functioning scale $(-13 \cdot 1 ; 95 \% \mathrm{CI}-25 \cdot 6,-0 \cdot 6)$, social functioning scale $(-12 \cdot 6 ; 95 \% \mathrm{CI}-21 \cdot 9,-3 \cdot 3)$, summary score $(-6 \cdot 4 ; 95 \% \mathrm{CI}-12 \cdot 3$, $-0 \cdot 4)$ and higher levels of fatigue (10.8; $95 \% \mathrm{CI} 0 \cdot 1,21 \cdot 5)$ compared with participants reporting moderate alcohol consumption. No 
Table 1. Demographic, lifestyle and clinical characteristics of colorectal cancer survivors (Mean values and standard deviations; numbers and percentages)

\begin{tabular}{|c|c|c|c|c|c|c|}
\hline & \multicolumn{2}{|c|}{ Total $(n 150)$} & \multicolumn{2}{|c|}{ Male ( $n$ 93) } & \multicolumn{2}{|c|}{ Female ( $n 57)$} \\
\hline & $n$ & $\%^{*}$ & $n$ & $\%^{*}$ & $n$ & $\%^{*}$ \\
\hline \multicolumn{7}{|l|}{ Age (years) } \\
\hline Mean & \multicolumn{2}{|c|}{$69 \cdot 7$} & \multicolumn{2}{|c|}{$69 \cdot 8$} & \multicolumn{2}{|c|}{$69 \cdot 6$} \\
\hline $\mathrm{SD}$ & \multicolumn{2}{|c|}{8.7} & \multicolumn{2}{|c|}{$8 \cdot 0$} & \multicolumn{2}{|c|}{$9 \cdot 8$} \\
\hline \multicolumn{7}{|l|}{ Time since diagnosis (years) } \\
\hline Mean & \multicolumn{2}{|c|}{$5 \cdot 7$} & \multicolumn{2}{|c|}{$5 \cdot 7$} & \multicolumn{2}{|c|}{$5 \cdot 6$} \\
\hline SD & \multicolumn{2}{|c|}{1.8} & \multicolumn{2}{|c|}{$1 \cdot 8$} & \multicolumn{2}{|c|}{$1 \cdot 8$} \\
\hline \multicolumn{7}{|l|}{ BMI† (kg/m²) } \\
\hline Mean & \multicolumn{2}{|c|}{$27 \cdot 7$} & \multicolumn{2}{|c|}{27.4} & \multicolumn{2}{|c|}{$28 \cdot 1$} \\
\hline SD & \multicolumn{2}{|c|}{$4 \cdot 3$} & \multicolumn{2}{|c|}{3.4} & \multicolumn{2}{|c|}{$5 \cdot 6$} \\
\hline Underweight and healthy weight $\leq 24.9$ & 38 & $26 \cdot 2$ & 21 & $22 \cdot 6$ & 18 & $32 \cdot 1$ \\
\hline Overweight $25 \cdot 0-29.9$ & 68 & $45 \cdot 6$ & 53 & $57 \cdot 0$ & 15 & $26 \cdot 8$ \\
\hline Obese $\geq 30.0$ & 42 & $28 \cdot 2$ & 19 & $20 \cdot 4$ & 23 & $41 \cdot 1$ \\
\hline \multicolumn{7}{|l|}{ Number of co-morbidities $†$} \\
\hline 0 & 37 & $24 \cdot 8$ & 25 & $26 \cdot 9$ & 12 & 21.4 \\
\hline 1 & 37 & $24 \cdot 8$ & 24 & $25 \cdot 8$ & 13 & $23 \cdot 2$ \\
\hline$\geq 2$ & 75 & $50 \cdot 3$ & 44 & $47 \cdot 3$ & 31 & 55.4 \\
\hline Smoking & & & & & & \\
\hline Current & 16 & $10 \cdot 7$ & 12 & $12 \cdot 9$ & 4 & $7 \cdot 0$ \\
\hline Non-current & 134 & $89 \cdot 3$ & 81 & $87 \cdot 1$ & 53 & $93 \cdot 0$ \\
\hline Moderate-to-vigorous physical activity (min & & & & & & \\
\hline$<150$ & 14 & $9 \cdot 3$ & 3 & $3 \cdot 3$ & 11 & $18 \cdot 3$ \\
\hline$\geq 150$ & 136 & $90 \cdot 7$ & 90 & $96 \cdot 8$ & 46 & $80 \cdot 7$ \\
\hline Education & & & & & & \\
\hline Low & 37 & $24 \cdot 7$ & 19 & $20 \cdot 4$ & 18 & 31.6 \\
\hline Medium & 51 & 34.0 & 30 & $32 \cdot 3$ & 21 & $36 \cdot 8$ \\
\hline High & 62 & $41 \cdot 3$ & 44 & $47 \cdot 3$ & 18 & $31 \cdot 6$ \\
\hline Cancer type & & & & & & \\
\hline Colon & 80 & $53 \cdot 3$ & 40 & 43.0 & 40 & $70 \cdot 2$ \\
\hline Rectosigmoid and rectum & 70 & $46 \cdot 7$ & 53 & $57 \cdot 0$ & 17 & $29 \cdot 8$ \\
\hline Tumour stage & & & & & & \\
\hline Stage I & 41 & 28.9 & 24 & $28 \cdot 2$ & 17 & $29 \cdot 8$ \\
\hline Stage II & 52 & $36 \cdot 6$ & 31 & $36 \cdot 5$ & 21 & $36 \cdot 8$ \\
\hline Stage III & 49 & 34.5 & 30 & $35 \cdot 3$ & 19 & $33 \cdot 3$ \\
\hline Cancer treatment & & & & & & \\
\hline Radiotherapy (yes) & 58 & $38 \cdot 7$ & 43 & $46 \cdot 2$ & 15 & $26 \cdot 3$ \\
\hline Chemotherapy (yes) & 79 & $52 \cdot 7$ & 50 & $53 \cdot 8$ & 29 & $50 \cdot 9$ \\
\hline Stoma & & & & & & \\
\hline No & 125 & $83 \cdot 3$ & 77 & $82 \cdot 8$ & 48 & $84 \cdot 2$ \\
\hline Yes & 25 & $16 \cdot 7$ & 16 & $17 \cdot 2$ & 9 & $15 \cdot 8$ \\
\hline
\end{tabular}

* Percentages may not add to 100 due to rounding.

† Data missing for one participant (female).

‡ Data missing for eight participants (male)

statistically significant associations were found for heavy $v$. moderate drinkers and for alcohol analysed as a continuous variable.

\section{Sensitivity analyses}

When excluding participants with outliers for ratio of energy intake to BMR ( $n$ 1) and values exceeding three times the interquartile range from the upper quartile of the fifth nutrient quintile ( $n$ 5), we found mostly similar associations except for the association between sugar-sweetened drinks and HRQoL. After excluding outliers $(n 6)$, higher intake of sugar-sweetened drinks was associated with lower HRQOL according to the EORTC summary score $(\beta / 250 \mathrm{~g}$ increase $-4 \cdot 6 ; 95 \%$ CI $-8 \cdot 7,-0.5)$ and higher fatigue on both the EORTC fatigue subscale and fatigue measured by the CIS (9.1; $95 \%$ CI $1 \cdot 6,16 \cdot 6$ and $12 \cdot 6$; $95 \%$ CI 3.3, 22.0, respectively). Results from additional sensitivity analyses by logistic regression models with dichotomised patient-reported outcomes were comparable to the results of the linear regression analyses, which therefore appeared to be robust for non-normality of patient-reported outcomes (results not shown).

\section{Discussion}

In this cross-sectional study of 150 stage I-III CRC survivors on average 5.7 years post-diagnosis, we analysed how the individual dietary recommendations of the WCRF/AICR for cancer prevention were related to several patient-reported outcomes using quantitative data from 7-d dietary records. While there is consensus amongst researchers that dietary patterns, rather than individual components (specific nutrients or food) are closely associated with health, the potential role of food groups cannot be ignored. After adjusting for clinical, demographic and other lifestyle factors, we found increased fruit and vegetable consumption combined to be associated with better physical 
Table 2. Dietary World Cancer Research Fund and American Institute for Cancer Research (WCRF/AICR) recommendations and adherence in a colorectal cancer survivor population $(n 150)^{*}$

\begin{tabular}{|c|c|c|c|c|c|}
\hline & & & Score & Adherence $(n)$ & $\%$ \\
\hline \multirow[t]{8}{*}{1.} & \multirow[t]{8}{*}{ Eat a diet rich in wholegrains, vegetables, fruit and beans } & \multicolumn{4}{|l|}{ Fruit and vegetables $(\mathrm{g} / \mathrm{d})$} \\
\hline & & $\geq 400$ & 0.5 & 27 & $18 \cdot 0$ \\
\hline & & 200 to $<400$ & 0.25 & 82 & $54 \cdot 7$ \\
\hline & & $<200$ & 0 & 41 & $27 \cdot 3$ \\
\hline & & \multicolumn{4}{|l|}{ Total dietary fibre $(\mathrm{g} / \mathrm{d})$} \\
\hline & & $\geq 30$ & 0.5 & 14 & $9 \cdot 3$ \\
\hline & & 15 to $<30$ & 0.25 & 107 & 71.3 \\
\hline & & $<15$ & 0 & 29 & $19 \cdot 3$ \\
\hline \multirow[t]{4}{*}{2.} & \multirow{4}{*}{$\begin{array}{l}\text { Limit consumption of 'fast foods' and other processed } \\
\text { food high in fat, starches or sugars }\end{array}$} & \multicolumn{4}{|c|}{ Percentage of total energy from adapted ultra-processed foods } \\
\hline & & Tertile 1 & 1 & 50 & $33 \cdot 3$ \\
\hline & & Tertile 2 & 0.5 & 50 & 33.3 \\
\hline & & Tertile 3 & 0 & 50 & 33.3 \\
\hline \multirow[t]{4}{*}{3.} & \multirow[t]{4}{*}{ Limit consumption of red and processed meat } & \multicolumn{4}{|c|}{ Total red meat (g/week) and processed meat ( $\mathrm{g} /$ week) } \\
\hline & & Red meat $<500$ and processed meat $<21$ & 1 & 2 & 1.3 \\
\hline & & $\begin{array}{l}\text { Red meat }<500 \text { and processed } \\
\text { meat } 21 \text { to }<100\end{array}$ & 0.5 & 17 & $11 \cdot 3$ \\
\hline & & Red meat $>500$ or processed meat $\geq 100$ & 0 & 131 & $87 \cdot 3$ \\
\hline \multirow[t]{4}{*}{4.} & \multirow[t]{4}{*}{ Limit consumption of sugar-sweetened drinks } & Total sugar-sweetened drinks $(\mathrm{g} / \mathrm{d})$ & & & \\
\hline & & 0 & 1 & 48 & $32 \cdot 0$ \\
\hline & & $>0$ to $\leq 250$ & 0.5 & 89 & $59 \cdot 3$ \\
\hline & & $>250$ & 0 & 13 & 8.7 \\
\hline \multirow[t]{4}{*}{5.} & \multirow[t]{4}{*}{ Limit alcohol consumption } & Total ethanol $(\mathrm{g} / \mathrm{d})$ & & & \\
\hline & & 0 & 1 & 18 & $12 \cdot 0$ \\
\hline & & $>0$ to $\leq 10$ & 0.5 & 51 & $34 \cdot 0$ \\
\hline & & $>10$ & 0 & 81 & $54 \cdot 0$ \\
\hline
\end{tabular}

* Scoring system is based on the National Cancer Institute operationalisation of the 2018 WCRF/AICR recommendations.

Table 3. Mean dietary intake in colorectal cancer survivors $(n 150)$

(Mean values and standard deviations)

\begin{tabular}{|c|c|c|c|c|c|c|}
\hline & \multicolumn{2}{|c|}{ Total $(n 150)$} & \multicolumn{2}{|c|}{ Male $(n$ 93) } & \multicolumn{2}{|c|}{ Female ( $n 57)$} \\
\hline & Mean & SD & Mean & SD & Mean & SD \\
\hline Total energy intake (kJ/d) & 8203.4 & $2003 \cdot 1$ & $9126 \cdot 4$ & $1753 \cdot 1$ & 6697.4 & $1379 \cdot 7$ \\
\hline Fruit and vegetables $(\mathrm{g} / \mathrm{d})$ & $272 \cdot 8$ & $131 \cdot 3$ & 274.5 & 129.7 & $270 \cdot 0$ & $135 \cdot 0$ \\
\hline Fruit $(g / d)$ & $131 \cdot 0$ & 94.2 & 131.4 & 96.9 & $130 \cdot 3$ & 90.5 \\
\hline Vegetables $(\mathrm{g} / \mathrm{d})$ & $141 \cdot 6$ & $70 \cdot 0$ & 143.1 & $68 \cdot 3$ & 139.5 & 73.4 \\
\hline Dietary fibre (g/d) & $21 \cdot 1$ & 6.9 & 23.1 & $7 \cdot 2$ & 17.8 & $5 \cdot 0$ \\
\hline Energy density $(\mathrm{kJ} / 100 \mathrm{~g}$ per $\mathrm{d})$ & $701 \cdot 0$ & 111.8 & $714 \cdot 2$ & $103 \cdot 9$ & 679.6 & 121.4 \\
\hline Fast foods (EN \%) & 31.4 & 11.1 & 29.0 & $9 \cdot 2$ & 35.2 & $12 \cdot 9$ \\
\hline Sugar-sweetened drinks (g/d) & $97 \cdot 1$ & $150 \cdot 1$ & 111.9 & $175 \cdot 6$ & $72 \cdot 8$ & 91.1 \\
\hline Red meat (g/week) & $592 \cdot 2$ & 294.9 & $671 \cdot 0$ & $304 \cdot 2$ & $463 \cdot 7$ & 228.6 \\
\hline Processed meat (g/week) & $315 \cdot 3$ & 223.9 & 382.7 & 238.4 & $205 \cdot 2$ & 141.8 \\
\hline Alcohol $(g / d)$ & 14.7 & $15 \cdot 0$ & 19.4 & $16 \cdot 3$ & $7 \cdot 1$ & $8 \cdot 3$ \\
\hline
\end{tabular}

EN \%, energy percentage.

functioning and increased vegetable consumption alone to be associated with better physical functioning and global QoL and with less fatigue. By contrast, a higher intake of energy-dense food was found to be associated with worse physical functioning and more fatigue. Non-alcoholic drinkers had significantly lower levels of physical, role and social functioning, a lower EORTC summary score and higher levels of fatigue in comparison with participants who were moderate alcohol drinkers.

To the best of our knowledge, this is the first study to have assessed the relationship between all individual dietary recommendations and patient-reported outcomes in CRC survivors by quantitative data from 7-d dietary records. Two cross-sectional studies have previously examined how fruit and vegetable consumption are associated with HRQOL after CRC. Blanchard et al. found that participants meeting the recommendation of at least five servings of fruit and vegetables a day reported higher general HRQOL ${ }^{(35)}$. Similarly, Grimmett et al. found that meeting this recommendation was associated with higher global QoL and physical, role and cognitive functioning ${ }^{(20)}$. However, both cross-sectional studies assessed fruit and vegetable intake only by a single- or two-item question. The associations between fruit and vegetable intake and HRQoL found in our study appeared mostly driven by vegetable and not fruit intake. Previous studies have not investigated these separately, and our results need further replication. With regard to CIPN, no studies have been performed in CRC survivors, although a longitudinal study in breast 
Table 4. Associations between dietary recommendations and health-related quality of life outcomes $\uparrow$ $\beta$-Coefficients and $95 \%$ confidence intervals)

\begin{tabular}{|c|c|c|c|c|c|c|c|c|c|c|c|c|c|c|c|}
\hline & & \multicolumn{12}{|c|}{ EORTC QLQ-C30 } & \multirow{2}{*}{\multicolumn{2}{|c|}{$\begin{array}{c}\text { CIS } \\
\text { Fatigue }(n 138)\end{array}$}} \\
\hline & & \multicolumn{2}{|c|}{$\begin{array}{c}\text { Global QoL } \\
(n 140)\end{array}$} & \multicolumn{2}{|c|}{$\begin{array}{l}\text { Physical } \\
\text { functioning } \\
\text { ( } n 140)\end{array}$} & \multicolumn{2}{|c|}{$\begin{array}{l}\text { Role functioning } \\
\quad(n 140)\end{array}$} & \multicolumn{2}{|c|}{$\begin{array}{c}\text { Social } \\
\text { functioning } \\
(n 140)\end{array}$} & \multicolumn{2}{|c|}{$\begin{array}{l}\text { Summary score } \\
\text { ( } n 138)\end{array}$} & \multicolumn{2}{|c|}{ Fatigue $(n 140)$} & & \\
\hline \multirow[t]{2}{*}{ Fruit and vegetables $(100 \mathrm{~g} / \mathrm{d})$} & Unadj. & $2 \cdot 5^{*}$ & $0.2,4.8$ & $5 \cdot 1^{*}$ & $2 \cdot 6,7 \cdot 5$ & $2 \cdot 5$ & $-0.7,5.6$ & 0.3 & $-2 \cdot 1,2 \cdot 6$ & 1.3 & $-0.3,2 \cdot 8$ & $-2 \cdot 9^{*}$ & $-5 \cdot 6,-0.2$ & $-5 \cdot 1^{*}$ & $-8 \cdot 5,-1 \cdot 7$ \\
\hline & & 1.2 & $-1 \cdot 0,3 \cdot 5$ & $3 \cdot 2^{*}$ & 0.8 & 1 . & $-2 \cdot 0,4 \cdot 3$ & $-1 \cdot 3$ & $-3 \cdot 7,1 \cdot 1$ & 0.2 & & -1.6 & $-4.3,1 \cdot 1$ & $-3 \cdot 3$ & $-6.7,0.1$ \\
\hline \multirow[t]{2}{*}{ Fruit (50 g/d) } & Unadj. & 0.9 & $-0.7,2.5$ & $2 \cdot 5^{\star}$ & $0.7,4.3$ & 0.9 & $-1 \cdot 3,3 \cdot 2$ & -0.1 & $-1.7,1.6$ & 0.6 & $-0.4,1.7$ & -1.5 & $-3.4,0.3$ & $-2 \cdot 2$ & $-4 \cdot 6,0 \cdot 2$ \\
\hline & Adj. $\neq$ & -0.2 & $-1 \cdot 8,1 \cdot 3$ & 1.2 & $-0.5,2.8$ & -0.4 & $-2 \cdot 5,1 \cdot 8$ & $-1 \cdot 2$ & $-2 \cdot 8,0.4$ & -0.2 & $-1 \cdot 2,0 \cdot 8$ & -0.3 & $-2 \cdot 1,1 \cdot 6$ & -0.6 & $-2 \cdot 9,1 \cdot 7$ \\
\hline \multirow[t]{2}{*}{ Vegetables $(50 \mathrm{~g} / \mathrm{d})$} & Unadj. & $2 \cdot 7^{*}$ & $0.6,4.8$ & $4.4^{*}$ & $2 \cdot 0,6 \cdot 7$ & $2 \cdot 7$ & $-0.3,5 \cdot 7$ & 0.5 & $-1 \cdot 7,2 \cdot 7$ & 1.1 & $-0.4,2.5$ & $-2 \cdot 3$ & $-4 \cdot 8,0 \cdot 2$ & $-4 \cdot 9^{*}$ & $-8 \cdot 1,-1 \cdot 7$ \\
\hline & Adj. $\neq$ & $2 \cdot 6^{*}$ & $0.6,4.7$ & $3 \cdot 3^{*}$ & $1 \cdot 2,5 \cdot 5$ & $2 \cdot 7$ & $-0.3,5 \cdot 6$ & -0.1 & $-2 \cdot 3,2 \cdot 2$ & 0.9 & $-0.5,2 \cdot 3$ & $-2 \cdot 3$ & $-4 \cdot 8,0 \cdot 3$ & $-4 \cdot 5^{\star}$ & $-7 \cdot 6,-1 \cdot 4$ \\
\hline \multirow[t]{2}{*}{ Dietary fibre $(10 \mathrm{~g} / \mathrm{d})$} & Unadj. & $5 \cdot 1^{*}$ & $0.9,9.5$ & $7.0^{*}$ & $2 \cdot 2,11 \cdot 8$ & 5.9 & $-0 \cdot 1,12 \cdot 0$ & $1 \cdot 0$ & $-3.5,5 \cdot 4$ & 4.4 & $1 \cdot 7,7 \cdot 2$ & $-8 \cdot 0^{*}$ & $-13 \cdot 0,-3 \cdot 0$ & $-7 \cdot 0^{*}$ & $-13 \cdot 6,-0.5$ \\
\hline & Adj. $\neq$ & 1.4 & $-4 \cdot 3,7 \cdot 1$ & 1.7 & $-4 \cdot 3,7 \cdot 7$ & -0.6 & $-8.6,7.3$ & -2.5 & $-8.4,3.5$ & 1.5 & $-2 \cdot 1,5 \cdot 1$ & -4.7 & $-11 \cdot 4,2 \cdot 0$ & $-3 \cdot 9$ & $-12.3,4.5$ \\
\hline \multirow[t]{2}{*}{ Fast foods (5 EN \%) } & Unadj. & $-1 \cdot 3$ & $-2 \cdot 6,0 \cdot 1$ & $-1 \cdot 3$ & $-2 \cdot 8,0 \cdot 3$ & $-1 \cdot 1$ & $-3 \cdot 0,0.8$ & -0.0 & $-1 \cdot 4,1 \cdot 4$ & $-1 \cdot 0^{*}$ & $-1 \cdot 9,-0.0$ & 0.6 & $-1 \cdot 1,2 \cdot 2$ & 0.8 & $-1 \cdot 3,2 \cdot 9$ \\
\hline & Adj.‡ & -0.6 & $-2 \cdot 0,0 \cdot 7$ & -0.5 & $-1 \cdot 9,1 \cdot 0$ & -0.2 & $-2 \cdot 1,1 \cdot 7$ & 0.4 & $-1 \cdot 1,1 \cdot 8$ & -0.4 & $-1 \cdot 3,0.5$ & -0.0 & $-1 \cdot 7,1 \cdot 6$ & 0.1 & $-1 \cdot 9,2 \cdot 1$ \\
\hline \multirow[t]{2}{*}{ Energy density $(100 \mathrm{~kJ} / 100 \mathrm{~g}$ per d) } & Unadj. & $-2 \cdot 1$ & $-4 \cdot 8,0.6$ & $-4 \cdot 8^{*}$ & $-7 \cdot 8,-1 \cdot 8$ & $-1 \cdot 3$ & $-5 \cdot 1,2 \cdot 6$ & -1.5 & $-4 \cdot 3,1 \cdot 3$ & -0.6 & $-2 \cdot 6,1 \cdot 3$ & $3 \cdot 2$ & $-0.0,6 \cdot 4$ & $4.8^{*}$ & $0.6,8.9$ \\
\hline & Adj.‡ & $-1 \cdot 0$ & $-3.9,1.9$ & $-4 \cdot 2^{*}$ & $-7 \cdot 1,-1 \cdot 2$ & -0.8 & $-4 \cdot 8,3.2$ & 0.3 & $-2 \cdot 7,3 \cdot 3$ & -0.4 & $-2 \cdot 4,1.6$ & $2 \cdot 6$ & $-0.8,6.0$ & 3.7 & $-0.6,8.0$ \\
\hline \multirow[t]{3}{*}{ Sugar-sweetened drinks $(250 \mathrm{~g} / \mathrm{d})$} & Unadj. & 3.4 & $-1.7,8.5$ & 1.7 & $-4 \cdot 1,7 \cdot 4$ & 1.7 & $-5.5,8.8$ & $-1 \cdot 2$ & $-6.4,3.9$ & 0.2 & $-3 \cdot 1,3.5$ & -0.2 & $-6 \cdot 2,5 \cdot 9$ & 1.2 & $-6.5,8.9$ \\
\hline & Adj. $\neq$ & 1.1 & $-4 \cdot 3,6 \cdot 5$ & $-3 \cdot 6$ & $-9 \cdot 2,2 \cdot 1$ & $-3 \cdot 4$ & $-10 \cdot 9,4.0$ & -3.4 & $-9 \cdot 1,2 \cdot 2$ & $-2 \cdot 6$ & $-6 \cdot 0,0 \cdot 8$ & 5.6 & $-0.7,11.9$ & $6 \cdot 3$ & $-1 \cdot 6,14 \cdot 2$ \\
\hline & Unadj. & 1.0 & $-0.1,2 \cdot 1$ & $1 \cdot 2$ & $-0.1,2.4$ & 1.4 & $-0.1,3 \cdot 0$ & 0.4 & $-0.7,1.5$ & 0.6 & $-0.2,1 \cdot 3$ & $-1 \cdot 1$ & $-2 \cdot 4,0.2$ & -0.5 & $-2 \cdot 2,1 \cdot 1$ \\
\hline Red meat $(100 \mathrm{~g} / \mathrm{d})$ & Adj. $\neq$ & 0.2 & $-1 \cdot 0,1 \cdot 4$ & 0.5 & $-0.7,1.8$ & 0.6 & $-1 \cdot 1,2 \cdot 3$ & 0.2 & $-1 \cdot 1,1 \cdot 5$ & -0.0 & $-0.8,0.7$ & -0.0 & $-1.4,1.4$ & 0.1 & $-1 \cdot 6,1.9$ \\
\hline Processed meat $(50 \mathrm{~g} / \mathrm{d})$ & Unadj. & 0.4 & $-0.4,1.1$ & 0.2 & $-0.7,1.0$ & 0.5 & $-0.6,1.5$ & -0.0 & $-0.8,0.7$ & 0.4 & $-0.1,0.9$ & -0.6 & $-1.4,0.3$ & -0.2 & $-1.3,0.9$ \\
\hline \multirow[t]{2}{*}{ Alcohol $(10 \mathrm{~g} / \mathrm{d})$} & Unadj. & 1.7 & $-0.4,3.7$ & 1.9 & $-0.4,4.3$ & $3 \cdot 2^{*}$ & $0.3,6.0$ & 1.2 & $-0.9,3.3$ & 1.0 & $-0.4,2.3$ & $-1 \cdot 0$ & $-3.4,1.5$ & -0.9 & $-4 \cdot 0,2 \cdot 3$ \\
\hline & Adj. $\neq$ & 1.0 & $-1 \cdot 2,3 \cdot 2$ & 0.1 & $-2 \cdot 2,2 \cdot 4$ & 1.4 & $-1 \cdot 7,4 \cdot 4$ & 1.8 & $-0.5,4.1$ & 0.5 & $-1.0,1.9$ & 0.3 & $-3 \cdot 0,3 \cdot 6$ & 0.3 & $-3.0,3.6$ \\
\hline
\end{tabular}

EORTC QLQ-C30, European Organization for the Research and Treatment of Cancer Quality of Life Questionnaire-core 30; CIS, Checklist Individual Strength; QoL, quality of life; Unadj., unadjusted; Adj., adjusted; EN\%, energy percentage. Statistically significant $(P<0.05)$

tSix dietitians reached consensus on the relevant differences for the dietary recommendations, based on the recommended portion per $\mathrm{d}$ and on relevant portion sizes.

F Adjusted for total energy intake (kJ/week), age (years), sex, BMI (kg/m²), moderate-to-vigorous physical activity (MVPA) (h/d), sedentary time (h/d), number of co-morbidities ( 0,1 and $\geq 2)$, smoking (current, non-current), education level (low, medium and high), tumour stages (I, II and III), chemotherapy (yes, no) and time since diagnosis (years). 
Table 5. Associations between dietary recommendations and neuropathy in chemotherapy patients ( $\beta$-Coefficients and $95 \%$ confidence intervals)

\begin{tabular}{|c|c|c|c|c|c|c|c|c|c|}
\hline & & \multicolumn{8}{|c|}{ EORTC QLQ-CIPN20 } \\
\hline & & \multicolumn{2}{|c|}{ Sum score $(n$ 122) } & \multicolumn{2}{|c|}{ Sensory scale ( $n$ 122) } & \multicolumn{2}{|c|}{ Motor scale ( $n$ 122) } & \multicolumn{2}{|c|}{ Autonomic scale $(n$ 124) } \\
\hline & & $\beta$ & $95 \% \mathrm{Cl}$ & $\beta$ & $95 \% \mathrm{Cl}$ & $\beta$ & $95 \% \mathrm{Cl}$ & $\beta$ & $95 \% \mathrm{Cl}$ \\
\hline \multirow{3}{*}{ Fruit and vegetables $(100 \mathrm{~g} / \mathrm{d})$} & Unadj. & 1.0 & $-2 \cdot 8,4 \cdot 9$ & 1.5 & $-2 \cdot 5,5 \cdot 6$ & 0.3 & $-3 \cdot 9,4 \cdot 5$ & 1.5 & $-2 \cdot 6,5 \cdot 7$ \\
\hline & Adj. $\ddagger$ & $1 \cdot 1$ & $-3 \cdot 5,5 \cdot 6$ & 1.4 & $-3 \cdot 5,6 \cdot 2$ & 0.7 & $-4 \cdot 1,5 \cdot 6$ & 0.6 & $-4 \cdot 1,5 \cdot 3$ \\
\hline & Unadj. & 0.1 & $-2 \cdot 7,3 \cdot 0$ & 0.5 & $-2 \cdot 6,3 \cdot 6$ & -0.3 & $-3 \cdot 5,2 \cdot 8$ & 0.6 & $-2 \cdot 5,3 \cdot 7$ \\
\hline Fruit (50 g/d) & Adj. $\ddagger$ & 0.6 & $-2 \cdot 7,3 \cdot 9$ & 0.7 & $-2 \cdot 9,4 \cdot 3$ & 0.5 & $-3 \cdot 0,4 \cdot 1$ & 0.8 & $-2 \cdot 6,4 \cdot 3$ \\
\hline \multirow[t]{2}{*}{ Vegetables $(50 \mathrm{~g} / \mathrm{d})$} & Unadj. & 1.4 & $-2 \cdot 0,4 \cdot 7$ & 1.7 & $-1 \cdot 8,5 \cdot 2$ & 0.9 & $-2 \cdot 7,4 \cdot 5$ & 1.5 & $-2 \cdot 1,5 \cdot 1$ \\
\hline & Adj. $\ddagger$ & 0.7 & $-3 \cdot 2,4.5$ & 1.0 & $-3 \cdot 1,5 \cdot 2$ & 0.4 & $-3 \cdot 8,4 \cdot 5$ & $-0 \cdot 3$ & $-4 \cdot 3,3 \cdot 7$ \\
\hline \multirow{2}{*}{ Dietary fibre $(10 \mathrm{~g} / \mathrm{d})$} & Unadj. & $-2 \cdot 4$ & $-9.7,4.9$ & 1.2 & $-6 \cdot 6,8 \cdot 9$ & $-6 \cdot 2$ & $-14 \cdot 0,1 \cdot 7$ & $-4 \cdot 4$ & $-12 \cdot 2,3 \cdot 4$ \\
\hline & Adj.‡ & 1.9 & $-8 \cdot 7,12.5$ & $6 \cdot 3$ & $-5 \cdot 0,17 \cdot 6$ & $-2 \cdot 1$ & $-13 \cdot 5,9 \cdot 3$ & -3.5 & $-14.4,7.5$ \\
\hline \multirow[t]{2}{*}{ Fast foods (5 EN \%) } & Unadj. & 1.0 & $-1 \cdot 3,3 \cdot 2$ & 0.3 & $-2 \cdot 1,2 \cdot 7$ & 1.8 & $-0.6,4 \cdot 3$ & 0.6 & $-1 \cdot 8,3 \cdot 1$ \\
\hline & Adj.‡ & $1 \cdot 0$ & $-1 \cdot 6,3 \cdot 6$ & 0.4 & $-2 \cdot 4,3 \cdot 2$ & 1.8 & $-0.9,4.6$ & 0.3 & $-2 \cdot 5,3.0$ \\
\hline \multirow{2}{*}{$\begin{array}{l}\text { Energy density } \\
\qquad(100 \mathrm{~kJ} / 100 \mathrm{~g} \text { per d) }\end{array}$} & Unadj. & -0.1 & $-4 \cdot 8,4.5$ & -0.8 & $-5 \cdot 7,4 \cdot 1$ & 0.2 & $-4 \cdot 9,5 \cdot 3$ & 1.9 & $-3 \cdot 1,6 \cdot 9$ \\
\hline & Adj. $\ddagger$ & $2 \cdot 4$ & $-4 \cdot 0,8 \cdot 8$ & $2 \cdot 0$ & $-4 \cdot 9,9 \cdot 0$ & 2.5 & $-4.5,9.4$ & 4.5 & $-1 \cdot 9,10 \cdot 8$ \\
\hline \multirow{2}{*}{$\begin{array}{l}\text { Sugar-sweetened drinks } \\
\qquad(250 \mathrm{~g} / \mathrm{d})\end{array}$} & Unadj. & 3.3 & $-6 \cdot 4,12 \cdot 9$ & 4.6 & $-5 \cdot 6,14 \cdot 8$ & 1.4 & $-9 \cdot 1,12 \cdot 0$ & $6 \cdot 6$ & $-2 \cdot 8,16 \cdot 0$ \\
\hline & Adj.‡ & $11 \cdot 1$ & $-1.9,24.1$ & 12.5 & $-1 \cdot 5,26 \cdot 6$ & 8.7 & $-5 \cdot 5,22 \cdot 9$ & $15 \cdot 7$ & $3 \cdot 9,27 \cdot 6^{*}$ \\
\hline \multirow{2}{*}{ Red meat $(100 \mathrm{~g} / \mathrm{d})$} & Unadj. & 0.2 & $-1 \cdot 9,2 \cdot 4$ & 1.0 & $-1 \cdot 3,3 \cdot 3$ & -0.5 & $-2 \cdot 8,1 \cdot 8$ & $-0 \cdot 3$ & $-2 \cdot 6,2 \cdot 0$ \\
\hline & Adj. $\ddagger$ & 1.6 & $-1 \cdot 2,4 \cdot 4$ & $2 \cdot 2$ & $-0.9,5.2$ & $1 \cdot 1$ & $-2 \cdot 0,4 \cdot 2$ & 1.4 & $-1 \cdot 6,4 \cdot 3$ \\
\hline \multirow[t]{2}{*}{ Processed meat $(50 \mathrm{~g} / \mathrm{d})$} & Unadj. & -0.2 & $-1.5,1.2$ & 0.0 & $-1.4,1.5$ & -0.3 & $-1 \cdot 7,1 \cdot 2$ & -0.7 & $-2 \cdot 1,0 \cdot 8$ \\
\hline & Adj.‡ & 0.4 & $-1 \cdot 7,2 \cdot 5$ & 0.3 & $-1 \cdot 9,2.6$ & 0.6 & $-1 \cdot 7,2 \cdot 9$ & 0.3 & $-1 \cdot 9,2.5$ \\
\hline \multirow[t]{2}{*}{ Alcohol $(10 \mathrm{~g} / \mathrm{d})$} & Unadj. & $-2 \cdot 5$ & $-6 \cdot 0,1 \cdot 1$ & $-2 \cdot 3$ & $-6 \cdot 0,1 \cdot 5$ & $-2 \cdot 8$ & $-6 \cdot 6,1 \cdot 1$ & $-2 \cdot 0$ & $-5 \cdot 8,1 \cdot 8$ \\
\hline & Adj.‡ & $-2 \cdot 2$ & $-6 \cdot 5,2 \cdot 1$ & $-2 \cdot 7$ & $-7.4,1.9$ & -1.5 & $-6 \cdot 2,3 \cdot 2$ & $-2 \cdot 2$ & $-6 \cdot 7,2 \cdot 3$ \\
\hline
\end{tabular}

EORTC QLQ, European Organization for the Research and Treatment of Cancer Quality of Life Questionnaire; CIPN, chemotherapy-induced peripheral neuropathy; Unadj., unadjusted; Adj., adjusted; EN \%, energy percentage.

${ }^{*}$ Statistically significant $(P<0.05)$.

† Six dietitians reached consensus on the relevant differences for the dietary recommendations, based on the recommended portion per $\mathrm{d}$ and on relevant portion sizes.

‡ Adjusted for total energy intake ( $\mathrm{kJ} /$ week), age (years), BMl ( $\left.\mathrm{kg} / \mathrm{m}^{2}\right)$, moderate-to-vigorous physical activity (MVPA) ( $\left.\mathrm{h} / \mathrm{d}\right)$, sedentary time ( $\left.\mathrm{h} / \mathrm{d}\right)$, number of co-morbidities ( $\left.0,1, \geq 2\right)$, smoking (current, non-current), education level (low, medium and high), tumour stages (I, II and III), chemotherapy (yes, no) and time since diagnosis (years).

cancer patients found no association between fruit and vegetable intake and $\mathrm{CIPN}^{(21)}$. These findings are in line with those presented here. The study of Grimmett et al. also considered alcohol intake. They found that moderate drinkers reported higher physical, role and social functioning and lower fatigue compared with non-drinkers and no significant association between heavy drinking (more than twenty-one and fourteen drinks per week in men and women, respectively) with $\mathrm{HRQOL}^{(20)}$. We also found that moderate drinkers had higher levels of physical functioning, role functioning, social functioning and an overall HRQOL score and lower levels of fatigue. However, we did not find a significant association between alcohol intake as a continuous variable and HRQoL. This is in line with research that shows that the relationship between alcohol consumption and health outcome is not a linear but may follow a 'J'-shaped relationship. Non-drinkers and heavy drinkers were shown to have poorer health outcomes compared with moderate drinkers ${ }^{(57)}$.

The 2018 WCRF/AICR lifestyle guidelines include a specific dietary recommendation focused on limiting 'fast foods', whereas the corresponding recommendation from the 2007 guidelines was focused on limiting energy-dense food. Based on the significantly changed description and content of this dietary recommendation, the operationalisation of this recommendation also needed to be adapted to a novel dietary assessment method for measuring fast foods via UPF consumption. It should be noted, though, that defining and operationalising the fast food group was of great difficulty ${ }^{(40)}$ and we therefore decided to also assess energy density of food as used in previous operationalisations. In our analyses, we observed no association between UPF intake and patient-reported outcomes. A higher percentage of UPF intake has been associated with overweight and obesity, a higher risk of developing hypertension, CVD and cancer (overall) and a higher likelihood of having asthma ${ }^{58,59)}$. We could not identify any other studies on UPF and patientreported outcomes with which to compare our results. However, we did observe an association between higher energy density and lower physical functioning. A possible explanation could be that by using UPF intake; we are trying to simplify a complex system. There are many different types of food processing and also the list of UPF varies a lot in terms of energy density and nutrient density (e.g. from white bread to pizza). Further research into optimising the operationalisation of the 'fast foods' recommendation of the WCRF/AICR guidelines is highly warranted.

The individual dietary WCRF/AICR recommendations form a package that, taken together, direct people towards healthy patterns of diet. The Mediterranean diet is a diet that encompasses many of the individual dietary WCRF/AICR recommendations. It is mainly a plant-based diet characterised by the consumption of large amounts of fruits, vegetables, legumes, nuts and seeds and whole grains. Intake of milk and dairy products, poultry and eggs is low to moderate, whereas red and processed meats, sweets and refined grains are consumed in low quantities. Finally, the Mediterranean diet is characterised by a moderate alcohol consumption, and in general, foods consumed in the Mediterranean region are minimally processed. The 
Mediterranean diet as a whole has been known for its protective role towards CRC incidence and other cancers ${ }^{(60-62)}$ However, evidence for the relationship of this type of diet with patient-reported outcomes in CRC survivors is currently still lacking. In this sample of CRC survivors, the prevalence of overweight was high, the intake of fruit and vegetables was low and meat consumption was high when compared with the cut-off values mentioned in the $2018 \mathrm{WCRF} / \mathrm{AICR}$ recommendations. Most CRC survivors did not adhere to the recommendations. Men and women are advised to eat $400 \mathrm{~g}$ of fruit and vegetables per $\mathrm{d}$. On average our participants did not meet this recommendation by far, with a mean intake of $141 \mathrm{~g}$ of vegetables and $131 \mathrm{~g} / \mathrm{d}$ of fruit instead. The advice for dietary fibre intake changed to $30 \mathrm{~g} / \mathrm{d}$ in the 2018 recommendations compared with $25 \mathrm{~g} / \mathrm{d}$ in the 2007 recommendation. Intakes in our study population were mostly lower than recommended, and because of the changed advice regarding fibre intake, adherence to this recommendation decreased from $29.7 \%$ adherence to the 2007 recommendation, to $9 \cdot 3 \%$ adherence to the 2018 recommendation ${ }^{(17)}$. UPF intake as a percentage of total daily energy consumed ranged in our participants from 4.4 to $63.4 \%$ with a mean consumption of $31.4 \%$ and energy density ranged from 443 to $1192 \mathrm{~kJ} / 100 \mathrm{~g}$ with a mean consumption of $701 \mathrm{~kJ} / 100 \mathrm{~g}$. No comparison could be made between adherence to the energy density recommendation ( $4 \cdot 1 \%)$ and the new fast food recommendation (33.3\%). In addition, the WCRF/AICR advises limiting the intake of red meat to 350-500 g/week and to not consume processed meat at all. Red meat and processed meat intakes in our population were higher than recommended; only two participants met the combination of this recommendation. Finally, the WCRF/AICR recommends not consuming any sugar-sweetened or alcoholic drinks. In our study, $32.0 \%$ of participants reported to not drink any sugar-sweetened drinks. As with dietary fibre, also a lower percentage of adherence for alcohol was seen between the 2018 recommendation compared with the 2007 recommendation. The recommendation for alcohol consumption changed from not drinking more than one glass of alcohol for women and two glasses of alcohol for men per d to not drinking alcohol at all. Consequently, adherence changed considerably from $64 \cdot 1 \%$ adherence to the 2007 recommendation to $12.0 \%$ adherence to the 2018 recommendation regarding alcohol consumption. The intakes reported in our CRC survivor sample were comparable to the Dutch population aged 51-79 years in the Dutch National Food Consumption Survey, albeit the WCRF/AICR dietary recommendations differed slightly in definition from how the Dutch National Food Consumption Survey classifies dietary groups ${ }^{(63)}$. This means that both for the CRC survivor population and for the Dutch population aged 51-79 years, there is still a lot to gain in order to meet adherence to the WCRF/AICR recommendations that is accompanied with risk reduction for cancer incidence ${ }^{(12)}$, but also linked to many other health benefits such as increased survival and less recurrence in cancer survivors ${ }^{(13-16)}$. Besides HRQoL benefits in the CRC survivors, adhering to the individual WCRF/AICR dietary recommendations could also have favourable effects on the well-being of the general population, as suggested by research on the Mediterranean diet in comparison with non-Mediterranean diet and increased fruit and vegetable consumption that was associated with better HRQOL ${ }^{(64-67)}$

A major strength of this study was the use of 7-d dietary records, which enabled quantitative assessment of food and beverage consumption and absolute intake of individual food and nutrients, which is more accurate than commonly used FFQ data $^{(68)}$. The information on individual food products enables making food groups with great precision. Portion sizes were measured, details on food preparation were reported, instructions on how to fill out the records were provided by dietitians, and, when needed, additional information from participants was requested, which improved the validity of reported food and drink consumption ${ }^{(69,70)}$. Additionally, assessment on multiple days makes the information gathered more reliable ${ }^{(68)}$. Also, memory limitations are not expected to be a source of error, since intakes are asked to be recorded at the time of intake ${ }^{(68)}$. Still, subjects may delay recording their intakes, alter their intake of food or not record their true intake due to social desirability or the relatively high burden of keeping a dietary record ${ }^{(68,70)}$. Because of social desirability, self-reported intake of for example fruit and vegetables may thus have been overestimated, while intake of energy-density and alcohol may have been underestimated. Adherence to the recommendations therefore also might have been slightly overestimated.

The main limitation of this study is the cross-sectional design. Consequently, we cannot draw any firm conclusions regarding the direction of the observed associations. Diet may have affected patient-reported outcomes, or patient-reported outcomes may have altered diet. The relationship between diet and HRQoL is likely complex and bidirectional ${ }^{(71)}$. In addition, our results might suffer from limited statistical power, especially for the CIPN outcomes. CIPN outcomes were only relevant for the subgroup of patients who received chemotherapy ( $n$ 65), and analyses were thus only performed within this group. As a result, findings for CIPN can be considered to be exploratory. Finally, we cannot rule out that some of our results may be false positives because of the potential for multiple testing and that residual confounding could be present even though we corrected for many relevant confounders. Another limitation of our study is that survival bias might have occurred since participants included in our study were generally younger and perhaps differed in other (non-measured) characteristics from non-participants. People that passed away before they could participate or who had a worse health and prognosis were not part of our study population, which may have affected the generalisability of our results to only the healthier subpopulation of long-term CRC survivors.

In summary, our results suggest that already partly adhering to the WCRF/AICR guidelines for a healthy diet may have favourable effects on the HRQOL and complaints of fatigue in the years after the end of CRC treatment. Future studies are needed to further investigate the relationship between diet and health outcomes in CRC survivors. In particular, there is a need for prospective research with longitudinal analyses to gain insight into the direction of associations between the dietary recommendations and HRQOL and for studies with larger sample sizes to investigate the role of diet in CIPN among chemotherapy-treated 
CRC survivors. Ideally, intervention studies should be performed to investigate whether adhering to these individual dietary recommendations result in better quality of life and decreased fatigue and CIPN. More evidence on the relation between dietary recommendations and patient-reported outcomes could eventually lead to the improvement and fine tuning of evidence-based lifestyle recommendations for CRC survivors.

\section{Acknowledgements}

The authors would like to thank all participants of the EnCoRe study and the health professionals in the Maastricht University Medical Centre+ involved in the recruitment of study participants. The authors would also like to thank the MEMIC centre for data and information management for facilitating the logistic processes and data management of our study. Finally, the authors would like to thank the research dietitians and research assistant who were mainly responsible for patient inclusion and performing home visits, as well as data collection and processing.

M. K. is funded by the Wereld Kanker Onderzoek Fonds (WKOF), as part of the World Cancer Research Fund International grant programme (grant no. 2017/1619). J. J. L. B.-P. was funded and J. L. K. is currently funded by Kankeronderzoekfonds Limburg as part of Health Foundation Limburg (grant no. 00005739). E. H. van R. is funded by the Wereld Kanker Onderzoek Fonds (WKOF), as part of the World Cancer Research Fund International grant programme (grant no. 2016/1620). The EnCoRe study was also funded by grants from the Stichting Alpe d'HuZes within the research programme 'Leven met kanker' of the Dutch Cancer Society (grant no. UM-2010-4867 and UM-2012-5653).

The authors' contributions are as follows: M. K., B. W. A. L. and M. J. L. B. contributed to analysing the data, interpretation of the findings and writing the original draft. M. P. W. and M. J. L. B. contributed to the study design, review and editing and supervision. J. J. L. B.-P., J. L. K., E. H. R., S. O. B. and F. M. reviewed and edited the manuscript. All authors read and approved the final version of the manuscript.

J. J. L. B.-P. has previously been employed in the health information department and is currently consultant for the healthy information programmes of Wereld Kanker Onderzoek Fonds (WCRF NL), the Netherlands. The authors declare that there are no conflicts of interest.

\section{Supplementary material}

For supplementary material referred to in this article, please visit https://doi.org/10.1017/S0007114520003487

\section{References}

1. Bray F, Ren JS, Masuyer E, et al. (2013) Global estimates of cancer prevalence for 27 sites in the adult population in 2008. Int J Cancer 132, 1133-1145.
2. Ferlay J, Soerjomataram I, Dikshit R, et al. (2015) Cancer incidence and mortality worldwide: sources, methods and major patterns in GLOBOCAN 2012. Int J Cancer 136, E359-E386.

3. Parry C, Kent EE, Mariotto AB, et al. (2011) Cancer survivors: a booming population. Cancer Epidemiol Biomarkers Prev 20, 1996-2005.

4. Chambers SK, Meng X, Youl P, et al. (2012) A five-year prospective study of quality of life after colorectal cancer. Qual Life Res 21, 1551-1564.

5. Jansen L, Koch L, Brenner H, et al. (2010) Quality of life among long-term ( $\geq 5$ years) colorectal cancer survivors - systematic review. Eur J Cancer 46, 2879-2888.

6. Marventano S, Forjaz M, Grosso G, et al. (2013) Health related quality of life in colorectal cancer patients: state of the art. BMC Surg 13, Suppl. 2, S15.

7. Thong MS, Mols F, Wang XS, et al. (2013) Quantifying fatigue in (long-term) colorectal cancer survivors: a study from the population-based patient reported outcomes following initial treatment and long term evaluation of survivorship registry. Eur J Cancer 49, 1957-1966.

8. Seretny M, Currie GL, Sena ES, et al. (2014) Incidence, prevalence, and predictors of chemotherapy-induced peripheral neuropathy: a systematic review and meta-analysis. Pain 155, 2461-2470.

9. Tofthagen C (2010) Surviving chemotherapy for colon cancer and living with the consequences. J Palliat Med 13, 1389-1391.

10. Bakitas MA (2007) Background noise: the experience of chemotherapy-induced peripheral neuropathy. Nurs Res $\mathbf{5 6}$, 323-331.

11. Mols F, Beijers T, Lemmens V, et al. (2013) Chemotherapyinduced neuropathy and its association with quality of life among 2- to 11-year colorectal cancer survivors: results from the population-based PROFILES registry. J Clin Oncol 31, 2699-2707.

12. WCRF/AICR (2018) Diet, Nutrition, Physical Activity and Cancer: A Global Perspective - Continuous Update Project Expert Report 2018. https://www.wcrf.org/dietandcancer (accessed July 2019).

13. Romaguera D, Ward H, Wark PA, et al. (2015) Pre-diagnostic concordance with the WCRF/AICR guidelines and survival in European colorectal cancer patients: a cohort study. BMC Med 13, 107.

14. Inoue-Choi M, Robien K \& Lazovich D (2013) Adherence to the WCRF/AICR guidelines for cancer prevention is associated with lower mortality among older female cancer survivors. Cancer Epidemiol Biomarkers Prev 22, 792-802.

15. Schwedhelm C, Boeing H, Hoffmann G, et al. (2016) Effect of diet on mortality and cancer recurrence among cancer survivors: a systematic review and meta-analysis of cohort studies. Nutr Rev 74, 737-748.

16. Van Blarigan EL \& Meyerhardt JA (2015) Role of physical activity and diet after colorectal cancer diagnosis. J Clin Oncol 33, 1825-1834.

17. Breedveld-Peters JJL, Koole JL, Muller-Schulte E, et al. (2018) Colorectal cancers survivors' adherence to lifestyle recommendations and cross-sectional associations with health-related quality of life. BrJ Nutr 120, 188-197.

18. van Veen MR, Mols F, Bours MJL, et al. (2019) Adherence to the World Cancer Research Fund/American Institute for Cancer Research recommendations for cancer prevention is associated with better health-related quality of life among long-term colorectal cancer survivors: results of the PROFILES registry. Support Care Cancer 27, 4565-4574.

19. Schlesinger S, Walter J, Hampe J, et al. (2014) Lifestyle factors and health-related quality of life in colorectal cancer survivors. Cancer Causes Control 25, 99-110. 
20. Grimmett C, Bridgewater J, Steptoe A, et al. (2011) Lifestyle and quality of life in colorectal cancer survivors. Qual Life Res 20, $1237-1245$.

21. Greenlee H, Hershman DL, Shi Z, et al. (2017) BMI, lifestyle factors and taxane-induced neuropathy in breast cancer patients: the pathways study. J Natl Cancer Inst 109, djw206.

22. Thraen-Borowski KM, Trentham-Dietz A, Edwards DF, et al (2013) Dose-response relationships between physical activity, social participation, and health-related quality of life in colorectal cancer survivors. J Cancer Surviv 7, 369-378.

23. Vallance JK, Boyle T, Courneya KS, et al. (2014) Associations of objectively assessed physical activity and sedentary time with health-related quality of life among colon cancer survivors. Cancer 120, 2919-2926.

24. Lynch BM, van Roekel EH \& Vallance JK (2016) Physical activity and quality of life after colorectal cancer: overview of evidence and future directions. Expert Rev Qual Life Cancer Care 1, 9-23.

25. Van Roekel EH, Bours MJ, Breedveld-Peters JJ et al. (2015) Light physical activity is associated with quality of life after colorectal cancer. Med Sci Sports Exerc 47, 2493-2503.

26. Mols F, Beijers AJ, Vreugdenhil G, et al. (2015) Chemotherapyinduced peripheral neuropathy, physical activity and healthrelated quality of life among colorectal cancer survivors from the PROFILES registry. J Cancer Surviv $\mathbf{9}, 512-522$

27. Adams SV, Ceballos R \& Newcomb PA (2016) Quality of life and mortality of long-term colorectal cancer survivors in the Seattle Colorectal Cancer Family Registry. PLOS ONE 11, e0156534.

28. Neefjes ECW, van den Hurk RM, Blauwhoff-Buskermolen S, et al. (2017) Muscle mass as a target to reduce fatigue in patients with advanced cancer. J Cachexia Sarcopenia Muscle 8, 623-629.

29. van Roekel EH, Bours MJL, Te Molder MEM, et al. (2017) Associations of adipose and muscle tissue parameters at colorectal cancer diagnosis with long-term health-related quality of life. Qual Life Res 26, 1745-1759.

30. Vissers PAJ, Martucci RB, Mols F, et al. (2017) The impact of body mass index and waist circumference on health-related quality of life among colorectal cancer survivors: results from the PROFILES Registry. Nutr Cancer 69, 1177-1184

31. Mosher CE, Sloane R, Morey MC, et al. (2009) Associations between lifestyle factors and quality of life among older long-term breast, prostate, and colorectal cancer survivors. Cancer 115, 4001-4009.

32. Sach TH, Barton GR, Doherty M, et al. (2007) The relationship between body mass index and health-related quality of life: comparing the EQ-5D, EuroQol VAS and SF-6D. Int $J$ Obes (Lond) 31, 189-196.

33. Blanchard CM, Stein K \& Courneya KS (2010) Body mass index, physical activity, and health-related quality of life in cancer survivors. Med Sci Sports Exerc 42, 665-671.

34. Trentham-Dietz A, Remington PL, Moinpour CM, et al. (2003) Health-related quality of life in female long-term colorectal cancer survivors. Oncologist 8, 342-349.

35. Blanchard CM, Courneya KS, Stein K, et al. (2008) Cancer survivors' adherence to lifestyle behavior recommendations and associations with health-related quality of life: results from the American Cancer Society's SCS-II. I Clin Oncol 26 2198-2204.

36. Vissers PA, Thong MS, Pouwer F, et al. (2016) Prospectively measured lifestyle factors and BMI explain differences in health-related quality of life between colorectal cancer patients with and without comorbid diabetes. Support Care Cancer 24, 2591-2601.

37. Gigic B, Boeing H, Toth R, et al. (2018) Associations between dietary patterns and longitudinal quality of life changes in colorectal cancer patients: the ColoCare Study. Nutr Cancer 70, 51-60.

38. Smith AG, Russell J, Feldman EL, et al. (2006) Lifestyle intervention for pre-diabetic neuropathy. Diabetes Care 29, 1294-1299.

39. Bunner AE, Wells CL, Gonzales J, et al. (2015) A dietary intervention for chronic diabetic neuropathy pain: a randomized controlled pilot study. Nutr Diabetes 5, e158.

40. Shams-White MM, Brockton NT, Mitrou P, et al. (2019) Operationalizing the 2018 World Cancer Research Fund/ American Institute for Cancer Research (WCRF/AICR) cancer prevention recommendations: a standardized scoring system. Nutrients 11, 1572.

41. van Roekel EH, Bours MJ, de Brouwer CP, et al. (2014) The applicability of the international classification of functioning, disability, and health to study lifestyle and quality of life of colorectal cancer survivors. Cancer Epidemiol Biomarkers Prev 23, 1394-1405.

42. Monteiro CA, Cannon G, Levy R, et al. (2016) NOVA. The star shines bright. World Nutrition 7, 28-38.

43. Aaronson NK, Ahmedzai S, Bergman B, et al. (1993) The European Organization for Research and Treatment of Cancer QLQ-C30: a quality-of-life instrument for use in international clinical trials in oncology. J Natl Cancer Inst 85, 365-376.

44. Pompili C, Koller M, Velikova G, et al. (2018) EORTC QLQ-C30 summary score reliably detects changes in QoL three months after anatomic lung resection for non-small cell lung cancer (NSCLC). Lung Cancer 123, 149-154.

45. Vercoulen JH, Swanink CM, Fennis JF, et al. (1994) Dimensional assessment of chronic fatigue syndrome. J Psychosom Res 38, 383-392.

46. Vercoulen JH, Hommes OR, Swanink CM, et al. (1996) The measurement of fatigue in patients with multiple sclerosis. A multidimensional comparison with patients with chronic fatigue syndrome and healthy subjects. Arch Neurol 53, 642-649.

47. Servaes P, van der Werf S, Prins J, et al. (2001) Fatigue in disease-free cancer patients compared with fatigue in patients with chronic fatigue syndrome. Support Care Cancer 9, 11-17.

48. Postma TJ, Aaronson NK, Heimans JJ, et al. (2005) The development of an EORTC quality of life questionnaire to assess chemotherapy-induced peripheral neuropathy: the QLQCIPN20. Eur J Cancer 41, 1135-1139.

49. Lavoie Smith EM, Barton DL, Qin R, et al. (2013) Assessing patient-reported peripheral neuropathy: the reliability and validity of the European Organization for Research and Treatment of Cancer QLQ-CIPN20 Questionnaire. Qual Life Res 22, 2787-2799.

50. Wendel-Vos GC, Schuit AJ, Saris WH, et al. (2003) Reproducibility and relative validity of the short questionnaire to assess health-enhancing physical activity. J Clin Epidemiol 56, 1163-1169.

51. Gezondheidsraad (2017) Beweegrichtlijnen 2017. Publication number 2017/08. Den Haag: Gezondheidsraad.

52. van Roekel EH, Winkler EA, Bours MJ, et al. (2016) Associations of sedentary time and patterns of sedentary time accumulation with health-related quality of life in colorectal cancer survivors. Prev Med Rep 4, 262-269.

53. World Health Organization (2011) Waist Circumference and Waist-hip Ratio: Report of a WHO Expert Consultation, Geneva, 8-11 December 2008. Geneva: WHO.

54. Sangha O, Stucki G, Liang MH, et al. (2003) The SelfAdministered Comorbidity Questionnaire: a new method to assess comorbidity for clinical and health services research. Arthritis Rheum 49, 156-163.

55. Black AE, Goldberg GR, Jebb SA, et al. (1991) Critical evaluation of energy intake data using fundamental principles of 
energy physiology: 2. Evaluating the results of published surveys. Eur J Clin Nutr 45, 583-599.

56. Welch AA, Luben R, Khaw KT, et al. (2005) The CAFE computer program for nutritional analysis of the EPIC-Norfolk food frequency questionnaire and identification of extreme nutrient values. J Hum Nutr Diet 18, 99-116.

57. Myint PK, Smith RD, Luben RN, et al. (2011) Lifestyle behaviours and quality-adjusted life years in middle and older age. Age Ageing 40, 589-595.

58. Monteiro CA, Cannon G, Lawrence M, et al. (2019) UltraProcessed Foods, Diet Quality, and Health Using the NOVA Classification System. Rome: FAO.

59. Fiolet T, Srour B, Sellem L, et al. (2018) Consumption of ultraprocessed foods and cancer risk: results from NutriNet-Sante prospective cohort. BMJ 360, k322.

60. Grosso G, Buscemi S, Galvano F, et al. (2013) Mediterranean diet and cancer: epidemiological evidence and mechanism of selected aspects. BMC Surg 13, Suppl. 2, S14.

61. Grosso G, Biondi A, Galvano F, et al. (2014) Factors associated with colorectal cancer in the context of the Mediterranean diet: a case-control study. Nutr Cancer 66, 558-565.

62. Borzi AM, Biondi A, Basile F, et al. (2018) Olive oil effects on colorectal cancer. Nutrients 11, 32.

63. Ocké MC, Buurma-Rethans EJM, Boer de EJ, et al. (2013) Diet of Community-Dwelling Older Adults - Dutch National Food Consumption Survey Older adults 2010-2012. Bilthoven: National Institute for Public Health and the Environment.
64. Henriquez Sanchez P, Ruano C \& de Irala J, et al. (2012) Adherence to the Mediterranean diet and quality of life in the SUN Project. Eur J Clin Nutr 66, 360-368.

65. Södergren M, McNaughton SA, Salmon J, et al. (2012) Associations between fruit and vegetable intake, leisure-time physical activity, sitting time and self-rated health among older adults: crosssectional data from the WELL study. BMC Public Health 12, 551.

66. Kwon SC, Wyatt LC, Kranick JA, et al. (2015) Physical activity, fruit and vegetable intake, and health-related quality of life among older Chinese, Hispanics, and Blacks in New York City. Am J Public Health 105, S544-S552.

67. Chai W, Nigg CR, Pagano IS, et al. (2010) Associations of quality of life with physical activity, fruit and vegetable consumption, and physical inactivity in a free living, multiethnic population in Hawaii: a longitudinal study. Int J Behav Nutr Phy 7, 83 .

68. Willett W (2013) Nutritional Epidemiology, 3rd ed. New York: Oxford University Press.

69. Institute of Medicine (US) Committee on Dietary Risk Assessment in the WIC Program (2002) Food-Based Assessment of Dietary Intake. Washington, DC: National Academies Press.

70. Ortega RM, Perez-Rodrigo C \& Lopez-Sobaler AM (2015) Dietary assessment methods: dietary records. Nutr Hosp 31, Suppl. 3, 38-45.

71. Jacka FN, Cherbuin N, Anstey KJ, et al. (2015) Does reverse causality explain the relationship between diet and depression? J Affect Disord 175, 248-250. 